\title{
Heterotic Groups, Gene Action and Heterosis Among Maize Inbred Lines Selected for the Major Agro-ecologies of Rwanda
}

\author{
Alphonse Nyombayire ${ }^{1,2, *}$, John Derera ${ }^{1,3}$, Julia Sibiya $^{1}$, Claver Ngaboyisonga ${ }^{2}$ \\ ${ }^{1}$ African Centre for Crop Improvement, University of KwaZulu-Natal, Pietermaritzburg, South Africa \\ ${ }^{2}$ Research and Technology Transfer Department, Rwanda Agriculture and Animal Resource Development Board, Kigali, Rwanda \\ ${ }^{3}$ International Institute of Tropical Agriculture, Ibadan, Nigeria
}

Email address:

alphonsenyombayire@yahoo.com (A. Nyombayire), dereraresearch@gmail.com (J. Derera), sibiyajules@gmail.com (J. Sibiya), c.ngaboyisonga@yahoo.com (C. Ngaboyisonga)

${ }^{*}$ Corresponding author

\section{To cite this article:}

Alphonse Nyombayire, John Derera, Julia Sibiya, Claver Ngaboyisonga. Heterotic Groups, Gene Action and Heterosis Among Maize Inbred Lines Selected for the Major Agro-ecologies of Rwanda. Journal of Plant Sciences. Vol. 9, No. 5, 2021, pp. 245-252.

doi: $10.11648 /$ j.jps.20210905.12

Received: July 20, 2021; Accepted: August 6, 2021; Published: September 26, 2021

\begin{abstract}
Maize breeding programmes exploit inbred lines with superior combining ability for grain yield and other agronomic traits to create competitive hybrids. Therefore, the objectives of this study were to determine heterotic groups of locally developed maize inbred lines, their heterotic relationships, with exotic testers as well as the gene action controlling grain yield. Nineteen maize inbred lines were crossed to four testers, based on a line $\mathrm{x}$ tester mating scheme resulting in 76 test crosses. These crosses were evaluated together with four checks in $10 \times 8 \alpha$-lattice design across four locations in 2015B and 2016A seasons. Both additive and non-additive gene action were important for grain yield with preponderance of additive gene action. The most desirable GCA effects for grain yield were realized in inbred line 8 while the highest desirable SCA effects were displayed by the test cross $18 \mathrm{xT1}$. Generally, most of the inbred lines exhibited positive heterosis with all testers. However, there was more aligning firstly towards tester T2 and then to T3. The highest heterosis was displayed by the combination of inbred line 8 with 3 . Regardless of the heterotic grouping method applied, the inbred lines were discriminated into different heterotic groups; two and nine heterotic groups were identified based on standard heterosis and SCA effects; respectively. The information generated would be useful in optimizing the maize hybrid breeding programme in Rwanda and for other researchers for high yielding maize variety development.
\end{abstract}

Keywords: Gene Action, Heterosis, Heterotic Group

\section{Introduction}

Worldwide and particularly in sub-Saharan Africa, maize (Zea mays L.) is a major staple cereal crop serving as human main diet especially for small income families and considerable production area is allocated to this crop [1-4].

In Rwanda, maize has become a leading crop in agricultural production and ranks first among pulse and grain crops production in Rwanda. It has seen an unprecedented development and radical changes [2, 5-6]. This increased maize production was mainly due to a shift in using only open pollinated varieties (OPVs) towards maize hybrids. However, these hybrids are imported from outside hence the need for development of local maize hybrids with high yield potential. After realizing this problem, the maize programme in Rwanda Agriculture and Animal Resource Development Board (RAB) focused on hybrid development using germplasm from various sources. Therefore, a large number of inbred lines were developed from different adapted and adopted OPVs.

Since knowledge of heterotic groups is important in any hybrid breeding programme [3, 7], this study aimed at addressing this aspect with a special focus on the inbred lines developed by the Rwandan maize breeding programme. Heterotic groups enable the exploitation of heterosis in an 
efficient as well as in a consistent manner through identification of complementary lines that can be used in the crosses. In addition, the heterotic groups can be used to reduce the number of germplasm in a breeding programme while preserving diversity within that germplasm. Heterotic grouping results in maximizing combining ability [8-9] while helping the breeder to make documented decisions on suitable hybrid combinations $[8,10]$, thus minimizing the possibility of assessing a high number of undesirable crosses. This concept was also reported [11-12] to be important for the development of climate-change resilient maize cultivars. Thus, breeders have been identifying multiple heterotic groups and patterns to improve maize hybrid breeding or monitor changes in heterotic patterns after prolonged breeding [10, 13-15].

Initiating a maize hybrid breeding programme requires well documented germplasm (parental lines) that can be used, and thus good identification and utilization of heterotic groups and patterns for these lines [8, 15-16]. Generally, broad populations, either from locally adapted or introductions have been used for breeding purposes. However, identification of promising heterotic groups has also been reported to result from diverse maize gene pools [11, 16-18]. Hence the knowledge regarding germplasm diversity and genetic relationships among breeding materials is invaluable in crop improvement strategies [18-19].

Furthermore, it has been reported that the best heterotic responses are obtainable when crosses are made between parents originating from genetically diverse populations $[10,11,21]$. Therefore, in any maize breeding programme, it is essential to establish the probable heterotic groups to ensure maximum exploitation of heterotic patterns as this will guide the choice of parents and breeding strategies for the success of maize hybrid production [11, 22] hence its implementation to the maize hybrid programme in Rwanda. Molecular markers are known as useful tools in evaluation of genetic diversity and relationships and then heterotic groups identification [11, 17]. Similarly, Information on heterotic groups could be availed through different mating schemes. However, with established testers for a hybridbreeding programme, the line $\mathrm{x}$ tester mating scheme, was earlier reported [23-24] to be simpler and effective in revealing the information. The design offers the possibility of crossing given germplasm to two or more genetically different testers. Consequently, this scheme was applied in the current study. Thus, this study was undertaken to determine heterotic groups prevailing in locally developed maize inbred lines, their heterotic relationships and mode of gene action.

\section{Materials and Methods}

\subsection{Germplasm, Field Evaluation and Measurements}

Nineteen maize inbred lines and four testers (T1-T4) (Table 1) were involved in the study. The inbred lines were derived from seven populations adapted to the mid-altitudes of Rwanda introduced from the International Maize and Wheat Improvement Center (CIMMYT). The four testers resulted from different genetic backgrounds and were introduced from CIMMYT (Ethiopia and Mexico). These testers were selected among many others based on their adaptability to local conditions and their genetic background. The lines were crossed with the testers, based on a line $\mathrm{x}$ tester mating scheme and generated 76 test crosses.

Table 1. Maize inbred lines and testers involved in the study.

\begin{tabular}{lllll}
\hline No & Line & Pedigree & Heterotic Group & Origin \\
\hline 1 & R10164 & ISARM101 5-6 (64) & Not Assigned (N/A) & Rwanda \\
2 & R10127 & ISARM101 2-3 (27) & N/A & Rwanda \\
3 & ACR3 & ACROSS8762 4-5 (3) & N/A & Rwanda \\
4 & ACRO4 & ACROSS8762 6-5 (4) & Rwanda \\
5 & ACRO4 & ACROSS8762 8-4 (25) & N/A & Rwanda \\
6 & ACRO29 & ACROSS8762 4-5 (29) & Rwanda \\
7 & ACR29 & ACROSS8762 4-9 (29) & N/A & Rwanda \\
8 & ECA1 & ECAVEL16-STR 9-4 (1) & N/A & Rwanda \\
9 & ECA1ECA5 & ECAVEL1/ECAVEL16-STR 3-10 (5) & Rwanda \\
10 & TQ7 & [TUXSEQ]C1 5-8 (7)II & N/A & Rwanda \\
11 & TQX31 & [TUXSEQ]C1 3-1 (31)I & N/A & Rwanda \\
12 & MZ1 & ZM607-38-4-1-B*4(1) & Rwanda \\
13 & MZ2 & ZM607-79-1-1-B*4(2) & Rwanda \\
14 & MZ3 & ZM607-38-1-1-B*4(3) & Rwanda \\
15 & POL1 & POOL32-70-2-1-B*4(1) & Rwanda \\
16 & POL2 & POOL32-76-1-1-B*4(2) & N/A & Nwanda \\
17 & POL4 & POOL32-17-1-1-B*4(4) & N/A & Rwanda \\
18 & POL6 & POOL32-6-1-1-B-B(6) & N/A & Rwanda \\
19 & POL7 & POOL32-6-3-1-B*4(7) & N/A & Rwanda \\
& Testers & & N/A & \\
20 & T1 & [POOL9Ac7-SR(BC2)]FS59-4-1-2-1-1-2-1-2-\#-\#-\#-\#-\# & \\
21 & T2 & SRSYN95[ECU//SC/ETO]F1-\#\#(GLS=3.5)-20-2-1-1-\#-\#-\#-\#-\# & Pool9A & Ecuador \\
22 & T3 & [KIT/SNSYN[N3/TUX]]c1F1-\#\#(GLS=2)-23-3-3-1-1-\# & Kitale & CIMMYT-Ethiopia \\
23 & T4 & Pool9AC6HM3-1-3-1-1-2P-2P-1-1-2-1-B-B & AB & CIMMYT-Ethiopia \\
\hline
\end{tabular}


The resulting 76 test crosses plus four checks were evaluated in an $8 \times 10$ alpha-lattice design. On the other hand, the 19 parental lines were evaluated in a randomized complete block design. Both experiments had two replications each with plots consisting of one row of $5.0 \mathrm{~m}$ (except Nyagatare site which was $4.0 \mathrm{~m}$ length in $16 \mathrm{~A}$ season) in length with $0.75 \mathrm{~m}$ and an intra-row spacing of $0.25 \mathrm{~m}$. They were planted on the same day and managed in the same way. At all sites, $200 \mathrm{~kg} / \mathrm{ha}$ of N-P-K (17-17-17). were applied at two weeks after planting. At six weeks after planting, $50 \mathrm{~kg} \mathrm{~N} /$ ha was top dressed using urea (46-0-0). Hand-weeding was done using the hoe when necessary to keep the plots free of weeds. In each agro-ecology, maize genotypes of similar vigour were used as borders.

The study was carried out in four research sites representative of major Rwandan maize growing agroecologies. Bugarama site; located in the semi-arid mid-altitude $\left(2^{\circ} 28 \mathrm{~S}, 29^{\circ} 00 \mathrm{E}, 900 \mathrm{~m}\right.$ asl) ranging from $900-1200$ metres above sea level (m asl), Nyagatare ( $1^{\circ} 20^{\prime} \mathrm{S}, 30^{\circ} 20^{\prime} \mathrm{E}, 1450$ masl) and Rubona $\left(2^{\circ} 29^{\prime} \mathrm{S}, 29^{\circ} 46^{\prime} \mathrm{E}, 1650\right.$ mas) located in the moist mid-altitude ranging from $1200-1700 \mathrm{~m}$ asl and Rwerere $\left(1^{\circ} 29^{\prime} \mathrm{S}, 29^{\circ} 52^{\prime} \mathrm{E} ; 2,100 \mathrm{~m}\right.$ asl) located in the highlands which are above $1700 \mathrm{~m}$ asl. The four sites were used in two consecutive seasons (2015B and 1206A) resulting in eight testing environments. Data were recorded on a plot basis and comprised different variables following standard procedures used at CIMMYT (CIMMYT, 1985). However, the current study focused on the following parameters: Grain yield $(\mathrm{t} / \mathrm{ha})$, as grain mass per plot adjusted to $12.5 \%$ moisture content. Field weight (FW) (weight of the harvested ears) per plot was multiplied by 0.80 shelling percentage to obtain grain yield (t/ha), adjusted to $12.5 \%$ grain moisture. Grain yield was computed based on the formula: Grain yield $(\mathrm{t} / \mathrm{ha})=$ field weight $(\mathrm{kg}) /[$ (plot size $) \times(100$-grain moisture content $) /(100$ 12.5) $\mathrm{x} 10 \times 0.8]$. Moisture content (MC) was measured as percentage grain moisture content using a moisture meter at harvest. Days to anthesis (AD), as number of days from planting to $50 \%$ of plants shedding pollen and days to silking (SD) as number of days from planting to $50 \%$ of plants showing silk emergence. Ears per plant (EPP) were determined as the number of ears with at least one fully developed grain, expressed as a fraction of the number of plants at harvest. Plant height $(\mathrm{cm})(\mathrm{PH})$ was measured as distance from the base of a plant to the auricle of the flag leaf, while ear height $(\mathrm{cm})(\mathrm{EH})$ was the distance between the ground level and the base of the primary earas.

\subsection{Statistical Analysis}

Analysis of variance within and across environments was performed using GLM SAS software programme [25] to test significant differences among the genotypes including checks. This was followed by the line $\mathrm{x}$ tester analysis following the general model:

$Y_{i j k}=n+r(e k)+e k+l i+t j+(1 x t) i j+(1 x e) i k+(t x e) j k+$ $(1 \times$ t $x$ e $)$ eijk + cijk
Where: $Y_{i j k}$ is the measured trait on genotype of ith line crossed with $\mathrm{jth}$ tester evaluated in $\mathrm{r}$ replications across $\mathrm{k}$ environments; $\mathrm{n}$ is the overall mean; $\mathrm{r}$ (ek) = effect of replication nested within ek environments; ek is the environmental main effects; 1 and $t$ are average effects of lines and testers; respectively which is equivalent to GCA effects of lines and testers, respectively; $1 \mathrm{x} t$ is line $\mathrm{x}$ tester interaction effects corresponding to the SCA effects of the crosses; $1 \mathrm{x}$ e, $\mathrm{t} \times \mathrm{e}$ and $1 \mathrm{x} \mathrm{x}$ e are the interactions of the lines, testers and the lines $\mathrm{x}$ testers with the environments, and eijk $=$ a random experimental error.

The Mixed linear model was adopted for data analysis. In the analysis, entries were regarded as fixed factors while sites, replications and incomplete blocks within a replication were considered as random factors. Test crosses variation was partitioned into tester and lines main effects then generating two independent estimates of GCA effects (GCA for testers and for lines), while the interaction of tester and line (tester $\times$ line) estimated the SCA effects [26, 27]. Furthermore, GCA effects for individual parents were computed as follows: $\mathrm{GCAl}=\mathrm{Xl}-\mu$ and $\mathrm{GCAt}=\mathrm{Xt}-\mu$, where: GCAl and GCAt $=$ GCA of female (line) and male (tester) parents, respectively; $\mathrm{Xl}$ and $\mathrm{Xt}=$ mean of the female and male parents, respectively; while $\mu=$ overall mean of all test crosses. The standard error (SE) for male and female GCA effects were also computed as follows: $\mathrm{MSEm}=$ $\mathrm{MSE} / \mathrm{rm}$ where $\mathrm{MSE}=$ mean square error $\mathrm{r}=\mathrm{reps} ; \mathrm{m}=$ number of males; $\mathrm{MSEf}=\mathrm{MSE} / \mathrm{rf}$ where $\mathrm{MSE}=$ mean square error, $r=$ reps; $f=$ number of females.

The effects of SCA were calculated as follows: $\mathrm{SCA}_{\mathrm{X}}=\mathrm{X}_{\mathrm{X}}$ - $\mathrm{E}\left(\mathrm{X}_{\mathrm{X}}\right)=\mathrm{X}_{\mathrm{X}}-[\mathrm{GCAl}+\mathrm{GCAt}+\mu]$, where: $\mathrm{SCA}_{\mathrm{X}}=\mathrm{SCA}$ effects of the two parents in the cross; $X_{X}=$ observed mean value of the cross; $E\left(X_{X}\right)=$ expected value of the cross based on the GCA effects of the two parents involved; GCAf and GCAm $=$ GCA of line and tester parents, respectively. The standard error (SE) for the SCA effects was also performed as follows: $\mathrm{SE}=\sqrt{ }(\mathrm{MSE} / \mathrm{r})$, Where: $\mathrm{MSE}=$ error mean square; $r=$ number of replications.

The significance of GCA and SCA effects were tested by dividing the corresponding GCA and SCA values by their respective standard error and then comparing the obtained $t$ with tabular t-value at error degrees of freedom.

Standard heterosis $(\mathrm{SH})$ was computed as $\mathrm{SH}=((\mathrm{F} 1-\mathrm{MT}) /$ MT) $* 100$, where MT $=$ Mean of the testers, best hybrid or the trial mean, F1 = F1 hybrid mean performance. Heterotic grouping was defined using SCA and heterosis. When a cross between inbred line and a tester exhibited high SCA estimates, then that inbred line was assigned in different heterotic group with that tester and the opposite applied when the cross exhibited low SCA estimates. Similarly, using standard heterosis, an inbred line was classified in the same heterotic group with a tester when there was low standard heterosis with regard to that inbred line relative to the tester and the opposite applied when a high standard heterosis was observed. 


\section{Results}

\subsection{Test Crosses Variation and Gene Action}

Mean squares for test crosses showed significant differences $(\mathrm{P}=0.05-0.001)$ for all traits measured (Table 2). However, their interactions with testing environments were also significant except for EPP. Lines mean squares considered as GCA females representing additive gene action were also significant for grain yield and other traits and similar results were observed for lines interaction with environments except for EPP and PH. However, lines mean squares magnitude were more important than the interaction.
With regards to mean squares of testers considered as male GCA effects representing additive gene action, significant differences were revealed for all traits and a similar trend was also realized for environment $\mathrm{x}$ testers except for EPP. Nonetheless, testers' mean squares magnitude were more important than the interaction.

Considered as SCA effects representing non-additive gene action, line $\mathrm{x}$ tester mean squares exhibited significant differences for all traits and a similar trend was observed in their interaction with environments except for EPP, PH and EH. However, the main effects were larger than the interactions.

Table 2. Mean squares for grain yield and other traits across eight environments.

\begin{tabular}{|c|c|c|c|c|c|c|c|}
\hline Source & DF & $\dagger \mathbf{G Y}$ & EPP & AD & SD & PH & EH \\
\hline Site & 7 & $639.82 * * *$ & $1.02 * * *$ & $48841.73 * * *$ & $49158.91 * * *$ & $179603.71 * * *$ & $62585.70 * * *$ \\
\hline Test crosses & 75 & $16.37 * * *$ & $0.14^{*}$ & $61.49 * * *$ & $101.63 * * *$ & $4941.00 * * *$ & $980.90 * * *$ \\
\hline Lines & 18 & $39.41 * * *$ & 0.15 & $161.95 * * *$ & $202.46 * * *$ & $7533.91 * * *$ & $1730.21 * * *$ \\
\hline Testers & 3 & $36.84 * *$ & $0.46^{* *}$ & $221.14 * * *$ & $837.57 * * *$ & 6611.59 & $5019.42 * * *$ \\
\hline Lines*Testers & 54 & $7.55 * * *$ & 0.12 & $19.33 * * *$ & $27.67 * * *$ & 3984.49 & $502.63 * * *$ \\
\hline Site*Test crosses & 525 & $4.01 * * *$ & 0.10 & $10.15 * * *$ & $11.60 * * *$ & 3472.00 & $226.40 *$ \\
\hline Site*Testers & 21 & $9.32 * * *$ & 0.12 & $26.49 * * *$ & $38.45 * * *$ & $6354.33 * *$ & $524.40 * * *$ \\
\hline Site*Lines*Testers & 378 & $3.40 * * *$ & 0.10 & $8.61 * * *$ & $9.27 *$ & 3267.18 & 201.25 \\
\hline Error & 600 & 2.01 & 0.10 & 5.77 & 7.73 & 3281.60 & 173.28 \\
\hline
\end{tabular}

$*, * *$, and $* * *$, indicate significance at $0.05,0.01$ and 0.001 probability, respectively

$\dagger \mathrm{AD}$, anthesis days; SD, silking days; EPP, ears per plant; GY, grain yield (t/ha); PH, plant height; EH, ear height.

Table 3. Estimates of general combining ability effects for grain yield and other traits across eight environments.

\begin{tabular}{|c|c|c|c|c|c|c|}
\hline Lines & $\dagger \mathbf{G Y}$ & EPP & AD & SD & $\mathbf{P H}$ & EH \\
\hline 1 & -0.31 & 0.01 & $-1.38 * * *$ & $-1.73 * * *$ & -7.95 & -1.11 \\
\hline 2 & 0.25 & -0.02 & $1.70 * * *$ & $1.63 * * *$ & -6.40 & $-5.40^{*}$ \\
\hline 3 & 0.38 & 0.03 & $2.29 * * *$ & $2.33 * * *$ & 5.20 & $7.29 * * *$ \\
\hline 4 & $0.59 *$ & -0.02 & $1.04 * *$ & $1.77 * * *$ & -8.85 & -1.17 \\
\hline 5 & $1.10 * * *$ & -0.03 & $2.08 * * *$ & $2.72 * * *$ & 4.25 & 2.42 \\
\hline 6 & -0.03 & -0.02 & 0.29 & $0.88^{+}$ & -1.15 & -1.63 \\
\hline 7 & $0.79 * * *$ & 0.04 & $1.73 * * *$ & $1.56^{* *}$ & 11.96 & $8.72 * * *$ \\
\hline 8 & $1.85 * * *$ & 0.04 & $2.11 * * *$ & $1.52 * *$ & $18.99 *$ & $9.63 * * *$ \\
\hline 9 & 0.32 & 0.07 & $-1.60 * * *$ & $-1.98 * * *$ & 6.86 & 0.86 \\
\hline 10 & $-1.38 * * *$ & 0.05 & -0.11 & 0.05 & $24.24 * *$ & -4.09 \\
\hline 11 & 0.33 & $0.14^{* *}$ & $1.33 * * *$ & $1.63 * * *$ & 1.26 & $6.03 * *$ \\
\hline 12 & -0.29 & -0.02 & -0.63 & -0.53 & -6.72 & -2.46 \\
\hline 13 & $-0.91 * * *$ & -0.06 & $-1.38 * * *$ & $-1.25 * *$ & 2.02 & $4.63 *$ \\
\hline 14 & $-0.66 * *$ & -0.08 & -0.55 & -0.39 & -8.30 & $-5.35^{*}$ \\
\hline 15 & $-0.62 * *$ & -0.04 & -0.27 & -0.56 & 2.30 & 0.17 \\
\hline 16 & $-0.91 * * *$ & -0.06 & $-2.00 * * *$ & $-2.27 * * *$ & -5.37 & $-4.41 *$ \\
\hline 17 & 0.31 & 0.01 & -0.66 & -0.55 & 2.11 & -0.33 \\
\hline 18 & -0.19 & 0.00 & -0.75 & $-0.94 *$ & -17.47 & -8.61 \\
\hline 19 & $-0.61 * *$ & -0.03 & $-3.25 * * *$ & $-3.83 * * *$ & -16.97 & $-4.73^{*}$ \\
\hline †SEL & 0.23 & 0.05 & 0.39 & 0.45 & 9.29 & 2.14 \\
\hline \multicolumn{7}{|l|}{ Testers } \\
\hline 20 (T1) & -0.05 & -0.02 & -0.50 & 0.17 & 3.21 & 4.37 \\
\hline 21 (T2) & 0.21 & -0.05 & 0.02 & 0.36 & 3.70 & 2.32 \\
\hline 22 (T3) & 0.31 & 0.05 & -0.71 & $-2.26^{*}$ & -0.52 & -4.59 \\
\hline 23 (T4) & -0.47 & 0.02 & 1.19 & $1.74 *$ & -6.40 & -2.00 \\
\hline SET & 0.50 & 0.11 & 0.85 & 0.98 & 20.25 & 4.65 \\
\hline
\end{tabular}

*, **, and ***, indicate significance at $0.05,0.01$ and 0.001 probability, respectively, $\uparrow \mathrm{AD}$, anthesis days; SD, silking days; EPP, ears per plant; GY, grain yield (t/ha); PH, plant height; EH, ear height; TLB, Turcicum leaf blight (score). $\$$ SEL and SET; Standard error for lines and testers, respectively. 


\subsection{General and Specific Combining Ability Estimates}

\subsubsection{Estimates of General Combining Ability Effects}

Estimates of GCA effects for grain yield as presented in Table 3 revealed that 10 inbred lines out of 19 exhibited significant differences. Among these, 4 of them displayed positive GCA effects, with inbred line 8 showing the highest (1.85 t/ha) significant positive GCA effects. This line also exhibited significantly different GCA effects in other traits under the current study except for EPP, however, with GCA effects of various signs. In the negative and significant GCA effects, inbred line (10) displayed the highest negative (-1.38 $\mathrm{t} / \mathrm{ha}$ ) value. With regards to testers involved in this study, none of them were significant for grain yield and this trend was also realized in other traits except testers T3 and T4 which showed significantly different GCA effects for SD, however with different signs.

For the other agronomic traits, in general lines showed different trends (Table 3); some lines had significant GCA effects with favorable and unfavorable signs depending on the trait and the corresponding lines. However, none of the lines exhibited significant GCA effects for EPP except for line 11.

\subsubsection{Estimates of Specific Combining Ability Effects}

With respect to estimates of SCA effects, most of the test crosses were not significant for grain yield and other traits (data not shown). The highest proportion (7\%) of significant test crosses was realized for grain yield while it was not significant in test crosses for some traits such as EPP. Regarding grain yield, both positive and negative significant SCA effects were observed. The highest and desirable significant positive $(3.81 \mathrm{t} / \mathrm{ha})$ SCA effect was displayed by the test cross $18 \times \mathrm{xT} 1$, while the lowest and undesirable significant negative $(-2.94 \mathrm{t} / \mathrm{ha})$ SCA effects was displayed by $12 \times \mathrm{xT} 3$ test cross. Lines 12 and 18 were involved in most of the test crosses displaying significant SCA effects.

\subsection{Heterosis and Heterotic Groups}

Standard heterosis for 76 test crosses computed relative to testers (T1-T4), trial mean, best check and mean of checks revealed that all the test crosses exhibited positive standard heterosis with all testers, with higher heterosis realized in test crosses with testers T1 and T2 (data not shown). With regards to the trial mean, $51 \%$ of the test crosses displayed positive standard heterosis with the highest value observed in the test crosses $8 / 22(48.9 \%)$ and 5/22 (36.03\%).

Relative to the best check, only $4 \%$ of the test crosses exhibited positive standard heterosis, while $51.3 \%$ displayed positive standard heterosis relative to the mean yield for the checks.

To document the inbred lines for their heterotic groups and orientations regarding grain yield, various tools were applied. Based on standard heterosis relative to the respective testers, inbred lines were aligned in two different groups: T1/T3/T4 and T1/T2/T3/T4 (data not shown). However, some of them displayed some common patterns somehow. The group T1/T3/T4 comprised only inbred line 14, while the remaining 18 lines aligned to T1/T2/T3/T4 group. Generally, most of the lines exhibited positive heterosis with all testers. However, there was more inclination firstly to tester T2 and then to T3 which had the highest heterosis with the maximum (354.62\%) displayed by line 8 with T3. On the contrary, line 14 showed the lowest $(96.34 \%)$ heterosis with T2.

By using SCA estimates for grain yield (Table 4), inbred lines were discriminated based on the four testers. The lines were assigned into different groups of the testers depending on the direction of the SCA estimate. Except inbred line 11 which aligned with T3 by showing negative SCA estimates, most of the other lines exhibited negative SCA estimates with more than one tester. It was realized that inbred line 12 had a negative sign for SCA estimates with all the testers. On the contrary, inbred line 18, showed consistent positive SCA estimates with all the testers.

Table 4. Heterotic alignment of 19 inbred lines based on SCA estimates for grain yield.

\begin{tabular}{lllllllll}
\hline \multirow{2}{*}{ Line } & \multicolumn{7}{c}{ SCA effects } & \multicolumn{7}{c}{ Grouping of Lines } \\
\cline { 2 - 8 } & T1 & T2 & T3 & T4 & †T1 & T2 & T3 & T4 \\
\hline 1 & -0.20 & 0.20 & -0.15 & 0.15 & + & & + & \\
2 & 0.78 & 0.06 & -0.32 & -0.52 & & & + & + \\
3 & 0.06 & 0.34 & -0.17 & -0.23 & & & + & + \\
4 & -0.64 & 0.57 & -0.11 & 0.18 & + & & + & \\
5 & -0.38 & -0.09 & 1.06 & -0.59 & + & + & & + \\
6 & -0.31 & 0.19 & -0.29 & 0.42 & + & & + & \\
7 & -0.19 & 0.05 & -0.08 & 0.21 & + & & + & \\
8 & 0.22 & -0.61 & 1.19 & -0.79 & & + & & + \\
9 & 0.01 & 0.61 & -0.92 & 0.30 & + & & + & \\
10 & -0.05 & 0.11 & 0.40 & -0.46 & + & & & + \\
11 & 0.03 & 0.06 & -0.48 & 0.39 & & & + & \\
12 & -2.71 & -1.25 & -2.94 & -1.89 & + & + & + & + \\
13 & 0.35 & -1.31 & 1.09 & -0.13 & & + & & + \\
14 & -0.05 & -2.00 & 0.62 & 1.43 & + & + & & + \\
15 & 0.29 & 0.62 & -0.90 & -0.01 & & & + & + \\
16 & -0.22 & 0.14 & 0.30 & -0.21 & + & & & + \\
17 & -0.43 & -0.15 & 0.84 & -0.27 & + & + & & + \\
18 & 3.81 & 2.18 & 1.84 & 2.57 & & & & + \\
19 & 0.04 & 0.68 & -0.57 & -0.14 & & & + & + \\
\hline
\end{tabular}

$\dagger \mathrm{T} 1 ; \mathrm{T} 2 ; \mathrm{T} 3$ and $\mathrm{T} 4$ testers: $\mathrm{T} 1=\operatorname{tester} 1, \mathrm{~T} 2=\operatorname{tester} 2, \mathrm{~T} 3=\operatorname{tester} 3$, and $\mathrm{T} 4=$ tester 4 .

\section{Discussion}

\subsection{Gene Action and Test Crosses Variation}

Significant differences among test crosses realized for all traits showed that the test crosses were adequately different from each other for these traits and thus implying a possibility of selecting most desirable test crosses for these traits. Similar findings were previously reported [5, 10, 20, 23].

Mean squares of lines and testers for grain yield and other traits representing GCA females and males, respectively were significant and greater than lines $\mathrm{x}$ testers mean squares suggesting preponderance of additive gene action. Therefore, selection procedures such as recurrent selection for GCA in the 
base populations could be applied for improvement of these traits. Furthermore, line $\mathrm{x}$ tester mean squares representing SCA effects were significant for grain yield and other traits, thus denoting the importance of non-additive gene action as well, indicating that these traits could be improved through development of hybrids between the complementary inbred lines and testers. The main effects showed interactions with environments, indicating different performances under different environments. However, the main effects mean squares were much higher such that they masked the effect of these interactions. Diverse ecologies and more replications for testing would be recommended for precise results. Similar findings were reported by other researchers working on different maize genotypes [5, 15, 28-31].

\subsection{Combining Ability Effects}

Estimates of GCA for individual lines revealed some favorable general combiners for grain yield. Among these, inbred line 8 showed the highest value (1.85 t/ha) and could thus contribute favorable alleles for the development of new varieties for increased yield. This line and others having similar GCA estimate patterns exhibited their value as testers in selection for high yield. These lines identified as good combiners could, therefore, be utilized in maize improvement programmes for improvement of the traits of interest as they have high potential of transferring desirable traits to their cross progenies in mid-altitudes and highlands. They can be used directly for hybrid production such as in three-way hybrids where they can be used as males and the single cross hybrids with high levels of heterosis as females. These results are in line with reports by by Rovaris et al. [29] and Bhagchand et al. [32]. On the contrary, other lines such as inbred line 10 showed negative significant GCA effects ($1.38 \mathrm{t} / \mathrm{ha}$ ) and were observed to be poor combiners contributing to reduced grain yield. The GCA estimate was reported by Rovaris et al. [29] as an important tool for the breeder to select better parents. This is because a low estimate, whether positive or negative, indicates that the GCA value of the parent, obtained based on its hybrid combinations, does not differ greatly from the general mean of the other populations assessed. On the other hand, high positive or negative GCA values indicate that the parent in question is greatly superior or inferior to the other parents in relation to mean progeny performance.

With regards to estimates of SCA effects, though most of the test crosses were not significant for grain yield, the highest positive and significant SCA estimates realized in test crosses such as 18xT1 implies the presence of good specific combiners in the germplasm under the current study. However, the opposite applies for some test crosses such as $12 \mathrm{xT} 3$ that showed the highest undesirable SCA effects for grain yield. Significant positive SCA effects for the test crosses indicated a significant deviation from what would have been predicted based on performance of the parents. Therefore, these test crosses with highly positive and significant estimates of SCA effect could be selected based on their specific combining ability and used in maize improvement programme.

In relation to testers involved in this study, none of them were significant for GCA effects for grain yield and this trend was also realized in other traits except testers T3 and T4 which showed significant GCA effects for SD although with different signs. Possibly, testing the current inbred lines using more testers could provide different trends with regard to GCA effects significance.

\subsection{Heterosis and Heterotic Groupings}

Genetic variation and heterosis are the basic reasons that many breeding programmes always prefer hybrid maize rather than open pollinated varieties or synthetic varieties [33-34]. Similarly, the positive standard heterosis values realized in the current study demonstrated the potential available in some of the test crosses. High heterosis exhibited with testers T1 and T4 implies that heterosis in the current germplasm could be maximized by crossing specific lines with these two testers. This was also emphasized in some specific test crosses that exhibited higher heterosis than the best checks showing their usefulness in the maize breeding programme than the current checks. This is in agreement with previous reports on the maize crop [15, 29, 33-34].

Relative to heterotic groups, though it was possible to reveal some patterns, heterotic grouping based on standard heterosis classified the lines into two groups (T1/T3/T4 and T1/T2/T3/T4) and each group comprising more than one tester. This implies that high heterosis could be expected from crosses of same inbred lines aligning with many testers. Therefore, breeding management of these inbred lines should take into account the two groups. Possibly, classifying these lines based on more/or other testers would have availed more clusters and specific heterotic groups not formed by one or two testers. Similar findings were earlier reported on different maize germplasm [10, 29].

However, using the magnitude of SCA estimates for grain yield, inbred lines were classified into nine groups. Inbred lines in crosses showing low magnitude of SCA effects were aligned to the same heterotic group, while those displaying high magnitude of SCA effects belonged to different heterotic groups $[10,15]$. Only two lines (9 and 11) were aligned to a heterotic group composed by one tester (T3) whereas the remaining lines were aligned to heterotic groups formed by more than one tester. Therefore, discriminating the current lines based on more testers would have enhanced the probabilities of identifying test crosses with larger specific combining ability effects and heterotic groups composed by one or two testers.

Discrepancies in number of heterotic groupings provided by SCA and heterosis grouping in maize were earlier reported by other researchers [14-15, 35] who pointed out that heterotic grouping can be influenced by the method used in assigning lines to the groups. Some lines 4, 6, 15 and 19 were aligned based on their origin and were consistent with their pedigree alignment and specific combing ability heterotic grouping. This was also in agreement with reports by Wegary et al. [15], though the germplasm used is different. 


\section{Conclusions and Recommendations}

In general, the results of this study revealed the importance of both additive and non-additive gene action in controlling grain yield and some other traits. Therefore, not only selection would be effective for yield improvement in the current germplasm but also in developing and identifying superior hybrids. The promising test crosses could be exploited for further breeding work as well as for direct release. Test crosses such as 18/T1, 18/T2 and 18/T4 displayed favorable SCA estimates for grain yield and they could be used directly as hybrids or potential single cross testers for development of three-way hybrids. The magnitude of standard heterosis observed in the current test crosses guarantees the development of commercial hybrids, as some of the test crosses outyielded the best check. Heterotic grouping based on different methods classified lines differently. However, regardless of the method used, the four testers discriminated the current lines in different heterotic groups allowing their rational breeding management and initiating hybrid breeding programme in Rwanda. Information generated from the current findings might be useful for laying a foundation for hybrid maize programme in Rwanda and for other researchers for high yielding maize variety development. However, we recommend that minor presence of non-additive effects observed in controlling grain yield should also be taken into account when using the current findings. This suggests that further breeding gain can be achieved through developing hybrids based on crosses with both high mean and specific combining ability effects.

\section{Acknowledgements}

This study was funded by the Alliance for a Green Revolution in Africa (AGRA) through the African Centre for Crop Improvement (ACCI) at the University of KwaZuluNatal. We acknowledge all Maize programme staff in Rwanda who assisted in trial management and data collection.

\section{References}

[1] Mukri G, Bhat JS, Gadag RN, Motagi BN, Manjunatha B, Kumar R \& Pal D (2020). Evaluation of inbred lines derived from commercial hybrids and their utilization in developing high yielding field corn (Zea mays L.) hybrids. Maydica 65 M 24.

[2] Niyibituronsa M, Mukantwali C, Nzamwita M, Hagenimana G, Niyoyita S, Niyonshima A, Hakizimana C, Ndilu L, Nyirahanganyamunsi G, Nkurunziza E, Sendegeya P, Niyonteze G, Muhutu JC, Shingiro JB, Umuhire J, Nyirahorana C, Ingabire AC, Nyiranshuti A, Sibomana E, Usabyembabazi M, Munganyinka E, Gasana AP, Kamaraba I, Izamuhaye JC, Nkundanyirazo E, Ngaboyisonga C, Bucagu C \& Karangwa P (2020). Assessment of aflatoxin fumonisin contamination levels in maize and mycotoxins awareness and risk factors in Rwanda. Afr. J Afr. J. Food Agric. Nutr. Dev. $2020 ; 20(5)$.
[3] Dao A, Sanou J, Gracen V \& Danquanh EY (2014). Heterotic relationship between INERA, CIMMYT and IITA maize inbred lines under drought and well-watered conditions. Maydica 59: 201-210.

[4] Ranum P, Pena-Rosas JP\& Garcia-Casal MN (2014). Global maize production, utilization, and consumption. Annals of the New York Academy of Sciences 1312: 105-112.

[5] Rwasimitana F, Ukozehasi C, Ngaboyisonga C \& Eva J (2021). Genotype by Environment Interaction and Yield Stability of Hybrid Maize Varieties Evaluated in Three Locations of Mid Altitudes of Rwanda. International Journal of Innovative Science and Research Technology 6: 184-192.

[6] NISR (2014). Seasonal Agriculture Survey 2014.

[7] Oppong A, Appiah-Kubi D, Ifie EB, Abrokwah AL, Ofori K, Offei KS, Adu-Dappah H, Mochiah BM \& Warburton LM (2019). Analyzing combining abilities and heterotic groups among Ghanaian maize landraces for yield and resistance/ tolerance to Maize Streak Virus Disease. Maydica 64: M27.

[8] Elmyhun M, Liyew C, Shita A \& Andualem M (2020). Combining ability performance and heterotic grouping of maize (Zea mays) inbred lines in testcross formation in Western Amhara, North West Ethiopia. Cogent Food \& Agriculture 6: 1727625.

[9] Barata C \&. Carena MJ (2006\}. Classification of North Dakota maize inbred lines into heterotic groups based on molecular and test cross data. Euphytica 151:339-349.

[10] Fato P, Derera J, Tongoona P, Makanda I \& Sibiya J (2012). Heterotic orientation of tropical maize inbred lines towards populations ZM523 and Suwan-1 under downy mildew infestation. Euphytica 187: 381-392.

[11] Nyombayire N, Derera J, Sibiya J, Gasura E \& Ngaboyisonga G (2016). Genetic diversity among maize inbred lines selected for the mid-altitudes and highlands of Rwanda. Maydica 61-2016.

[12] Prasanna B (2012). Diversity in global maize germplasm: characterization and utilization. Journal of Biosciences 37: 843-855.

[13] Katragadda S, Tekale P \& Dinasarapu S (2020). Identification of potential parental lines for single, three-way and double crosses in maize (Zea mays L.). Maydica 65: M 14.

[14] Richard C, Osiru D, Mwala M \& Lubberstedt T (2016). Genetic diversity and heterotic grouping of the core set of southern African and temperate maize (Zea mays L) inbred lines using SNP markers. Maydica 61- 2016.

[15] Wegary D, Vivek BS \& Labuschagne MT (2014). Combining Ability of certain agronomic traits in quality protein maize under stress and nonstress environments in eastern and southern Africa. Crop Sci 54: 1004-1014.

[16] Melani MD \& Carena MJ (2005). Alternative Maize Heterotic Patterns for the Northern Corn Belt. Crop Science 45: 21862194.

[17] Semagn K., Magorokosho C, Vivek BS, Makumbi B, Beyene Y \& Mugo S (2012). Molecular characterization of diverse CIMMYT maize inbred lines from eastern and southern Africa using single nucleotide polymorphic markers. BMC Genomics 1471-2164. 
[18] Hallauer AR., Carena MJ \& Filho JBM (2010). Quantitative genetics in maize breeding. 6th ed. Springer, Iowa, USA.

[19] Makore F, Magorokosho C, Dari S, Gasura E, Mazarura U, Kamutando CN \& Mhike X (2021). Genetic Evaluation and Correlation Analysis Among Various Quantitative Traits in Maize Single-Cross Hybrids Under Diverse Environments. Journal of Agricultural Science 13: 104-112.

[20] Mohammad QIM, Golam MdR, Aminul AKMI, Khaleque MAM, Nasrin AI \& Jalal UA (2016). Combining Ability and Heterosis in Maize (Zea mays L.). American Journal of BioScience 2016; 4 (6): 84-90.

[21] Dhliwayo T, Pixley K, Menkir A \& Warburton M (2009). Combining ability, genetic distances, and heterosis among elite CIMMYT and IITA tropical maize inbred lines. Crop Science 49: 201-210.

[22] Bidhendi M. Z, Choukan R, Darvish F, Mostafavi K, \& Majidi E (2012). Classifying of maize inbred lines into heterotic groups using diallel analysis. Environments 7: 2252.2250.

[23] Akula D, Patil A, Zaidi PH, Kuchanur PH, Vinayan M \&. Seetharam K (2015). Line $\times$ testers analysis of tropical maize inbred lines under heat stress for grain yield and secondary traits. Maydica 61: M5.

[24] Kempthorne O (1957). An introduction to genetic statistics. John Wiley and Sons, New York.

[25] SAS Institute (2002). The SAS system for Windows, Release 9.3. SAS Institute Inc., Cary.

[26] Kearsey MJP \& Harpal S (1996). The genetical analysis of quantitative traits. Springer Science.

[27] Hallauer A, \& Miranda J (988). Quantitative genetics in maize breeding Ames, Iowa State University press.
[28] Abdel-Moneam M, Sultan M, Salama S \& El Oraby A (2014). Evaluation of combining ability and heterosis for yield and its components traits of five maize inbreds under normal and stress nitrogen fertilization. Asian Journal of Crop Science 6: 142 .

[29] Rovaris SR, Zagatto ME \& Sawazaki E (2014). Combining ability of white corn genotypes with two commercial hybrids. Maydica 59: 96-103.

[30] Abrha SW, Zeleke HZ \& Gissa DW (2013). Line $x$ tester analysis of maize inbred lines for grain yield and yield related traits. Asian Journal of Plant Science and Research 3: 12-19.

[31] Musila RN, Diallo AO, Makumbi D \& Njoroge K (2010). Combining ability of early-maturing quality protein maize inbred lines adapted to Eastern Africa. Field Crops Research 119: 231-237.

[32] Bhagchand O, Dubey RB, Mohan S \& Ameta KB (2018). Combining ability analysis in medium maturing yellow seeded maize (Zea mays L.) hybrids. Journal of Pharmacognosy and Phytochemistry 7 (3): 1354-1359.

[33] Ali F, Shah I. A, Noor M, Khan MY, Ullah I and Yan J (2012). Heterosis for yield and agronomic attributes in diverse maize germplasm. Australian Journal of Crop Science 6: 455.

[34] Aditi G, Prakash KD, Amitava G \& Sabyaschi K (2018). Heterosis, Potence Ratio and Genetic Distance for yield and yield contributing traits in single cross maize hybrids. Maydica $63 \sim$ M9.

[35] Menkir A, Badu-Apraku B \& Adepoju A (2003). Evaluation of heterotic patterns of IITA's lowland white maize inbred lines [Zea mays L.-International Institute of Tropical AgricultureNigeria]. Maydica 48 (2003): 161-170. 